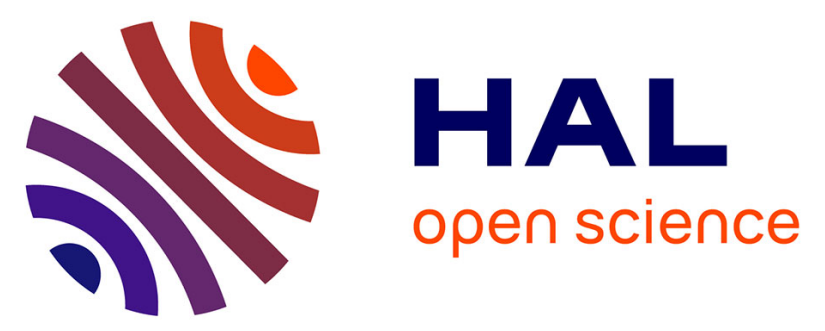

\title{
Chemical-by-chemical and cumulative risk assessment of residential indoor exposure to semivolatile organic compounds in France
}

Maud Pelletier, Philippe Glorennec, Corinne Mandin, Barbara Le Bot, Olivier Ramalho, Fabien Mercier, Nathalie Bonvallot

\section{To cite this version:}

Maud Pelletier, Philippe Glorennec, Corinne Mandin, Barbara Le Bot, Olivier Ramalho, et al.. Chemical-by-chemical and cumulative risk assessment of residential indoor exposure to semivolatile organic compounds in France. Environment International, 2018, 117, pp.22-32. 10.1016/j.envint.2018.04.024 . hal-01795814v2

\section{HAL Id: hal-01795814}

https://hal-univ-rennes1.archives-ouvertes.fr/hal-01795814v2

Submitted on 4 Sep 2018

HAL is a multi-disciplinary open access archive for the deposit and dissemination of scientific research documents, whether they are published or not. The documents may come from teaching and research institutions in France or abroad, or from public or private research centers.
L'archive ouverte pluridisciplinaire HAL, est destinée au dépôt et à la diffusion de documents scientifiques de niveau recherche, publiés ou non, émanant des établissements d'enseignement et de recherche français ou étrangers, des laboratoires publics ou privés. 
1 Chemical by chemical and cumulative risk assessment of residential indoor exposure to

2 semivolatile organic compounds in France

4 Maud Pelletier $^{1}$, Philippe Glorennec ${ }^{1 *}$, Corinne Mandin $^{2}$, Barbara Le Bot ${ }^{1}$, Olivier Ramalho ${ }^{2}$, 5 Fabien Mercier ${ }^{1}$, Nathalie Bonvallot ${ }^{1}$.

6

$7 \quad{ }^{1}$ Univ Rennes, EHESP, Inserm, Irset (Institut de recherche en santé, environnement et travail)

8 - UMR_S 1085, F-35000 Rennes, France

$9 \quad{ }^{2}$ University of Paris-Est, Scientific and Technical Center for Building (CSTB), Health and 10 Comfort Department, French Indoor Air Quality Observatory (OQAI), 84 Avenue Jean 11 Jaurès, Champs sur Marne, 77447 Marne la Vallée Cedex 2, France

$12{ }^{*}$ Corresponding author:

Univ Rennes, EHESP, Inserm, Irset (Institut de recherche en santé, environnement et travail) -

UMR_S 1085, F-35000 Rennes, France

Tel.: +33-2 99022680

E-mail address: philippe.glorennec@ehesp.fr

\section{Running Title: Health risk of indoor SVOCs in France}

Acknowledgments: this work was supported by a doctoral grant (Maud Pelletier) from the Fondation de France (grant number 2014-00053331) and the Agence de l'Environnement et de la Maîtrise de l’Énergie (grant number TEZ14-36).

21 The authors declare they have no competing financial interests. 
Mixture, health risk, public health, environmental health, contaminant.

\section{ABSTRACT}

Background: The toxic effects of environmental exposure to chemicals are increasingly being studied and confirmed, notably for semivolatile organic compounds (SVOCs). These are found in many products and housing materials, from which they are emitted to indoor air, settled dust and other surfaces. Objectives: The objective of this work is to assess the human health risk posed by residential indoor exposure to 32 SVOCs, assessed in previous nationwide studies. Methods: A chemical-by-chemical risk assessment, using a hazard quotient (HQ) or excess risk (ER) method, was supplemented by a cumulative risk assessment (CRA). For CRA, a hazard index (HI) method, as well as higher tier approaches using relative potency factors (RPFs) or toxic equivalency factors (TEFs) were used for the following endpoints: neurotoxicity, reproductive toxicity, genotoxicity and immunotoxicity. Results: HQs were above 1 for 50\% of French children from birth to 2 years for BDE 47, and for 5\% of children for lindane and dibutyl phthalate (DBP). Corresponding hazards are reprotoxic for BDE 47 and DBP, and immunotoxic for lindane. The CRA approach provided additional information of reprotoxic risks (HI>1) that may occur for $95 \%$ of children and for $5 \%$ of the offspring for pregnant women's exposure. The SVOCs contributing most to these risks were: PCB 101 and 118, BDE 47, and DBP. The higher tier CRA approaches showed that exposure to dwellings' SVOC mixtures were of concern for $95 \%$ of children for neurotoxic compounds having effects linked with neuronal death. To a lesser extent, effects mediated by the aryl hydrocarbon receptor $(\mathrm{AhR})$ or by a decrease in testosterone levels may concern $5 \%$ of children and adults. Lastly, unacceptable immunotoxic risk related to exposure to 8 indoor PCBs was also observed for $5 \%$ of children. Conclusions: In view of uncertainties related to 
compounds' toxicity for humans, these results justify the implementation of preventive measures, as well as the production of more standardized and comprehensive toxicological data for some compounds.

\section{INTRODUCTION}

People are exposed to an increasing number of chemicals, present in all media such as food, water, air, soil, clothes, etc. Exposure in residential indoor environments is of particular concern, due to their ubiquitous contamination and to the large amount of time people spent inside. Among chemicals found in dwellings, semivolatile organic compounds (SVOCs) represent a large class of organic compounds belonging to different chemical families and having a vapor pressure of between $10^{-14}$ and $10^{-4}$ atm (Weschler and Nazaroff 2008). Because of their diverse properties - plasticizer, flame retardant, biocide, etc. (Mercier et al., 2011), they are used in a wide range of materials and products (wall materials, furniture, household cleaning products, etc.). Their particular physical-chemical properties render them capable of migrating from their sources and partitioning between indoor air, settled dust and other surfaces (Weschler and Nazaroff 2010); people are thus exposed via inhalation, ingestion and dermal contact. A recent study has estimated aggregate exposure from measurement data for $32 \mathrm{SVOCs}$ from different chemical families, frequently detected in French dwellings (Pelletier et al., 2017a): 6 phthalates, 4 polycyclic aromatic hydrocarbons (PAHs), 2 organophosphorus (OPs), 3 organochlorines (OCs), 2 polycyclic musks, 8 polychlorinated biphenyls (PCBs), and 7 polybromodiphenylethers (PBDEs).

Many of these SVOCs are suspected of having adverse health effects. Some exhibit an endocrine disruption mechanism, leading to potential effects on male reproduction. This is the case for phthalates, which have been studied extensively in human and other mammals. Specific effects on testosterone synthesis have also been shown following rodent exposure to 
PBDEs (BDE 99) and PAHs (benzo[a]pyrene) (Fournier et al., 2016). They are also known to be neurotoxic in experimental mammals, and numerous epidemiological studies suggest an association between early-life exposure to SVOCs (OCs, OPs, PCBs, PBDEs, PAHs, and phthalates) and behavioral impairment later in life (Fournier et al., 2017). PAHs (especially benzo[a]pyrene) and some OCs or OPs pesticides are also known to be carcinogenic compounds (IARC 2010; Inserm 2013). Many SVOCs thus have common toxic effects, especially in early life, justifying cumulative risk assessment (CRA). For CRA we chose to focus i) on neurotoxicity, reproductive toxicity, and genotoxic carcinogenicity because these endpoints are related to systems which are particularly sensitive to chemical exposure during early life ii) on SVOCs with mixture based toxicological data when available.

CRA adresses exposure from multiple compounds, based on defined criteria such as chemical structure, mechanism of action, target organ or toxic effect (EFSA 2008; Boobis et al. 2008). These methods are usually based on the fundamental concept of additivity, and are described extensively elsewhere (Sarigiannis and Hansen 2012; Fournier et al., 2014a). The CRA issue is a challenging one, and a consensus has been reached that hierarchical approaches should be adopted, with each tier being more refined - more certain and less cautious - than the previous one (Meek et al., 2011).

The objective of this study, conducted within the framework of the ECOS project (Glorennec et al., 2011), was to assess the public health risk posed by 32 SVOCs. Briefly the ECOS project aimed to develop multi-residue analytical methods appropriate to indoor contamination (Mercier et al., 2012, 2014), as well as to measure indoor contamination in France (Mandin et al., 2016; Blanchard et al., 2014), group compounds on the basis of common toxicity (Fournier et al., 2014b), and develop mixture toxicity indicators (Fournier et al., 2016, 2017). Using nationwide measurements, we assessed exposure (by inhalation, contact and ingestion) to 32 indoor SVOCs on a population basis, that is, the distributions of 
exposure are representative of those of the population living in France (Pelletier et al., 2017b). A chemical-by-chemical risk assessment was completed using lower to higher tier CRA, as recommended by Meek et al. (2011), based on reference doses from risk assessment databases and mixture toxicity indicators from the literature.

\section{METHODS}

\section{Chemical-by-chemical risk assessment}

For non-carcinogenic SVOCs, hazard quotients (HQ, unitless) were calculated as follows:

$$
H Q=\frac{A D D}{R f D \times f_{\text {oral }}}
$$

With

ADD: Aggregate Daily Dose (mg/kg-bw/d)

RfD: Reference dose (mg/kg-bw/d)

$\mathrm{f}_{\text {oral }}$ : Oral bioavailability

ADDs were retrieved from a previous exposure study encompassing air inhalation, dust ingestion, and dermal contact and are expressed as internal doses; 32 SVOCs were selected on the basis of their health interest and because they were detected in both the air and the settled dust of French dwellings (Pelletier et al. 2017b). Briefly, in this previous study, ADDs were simulated on the basis on nationwide representative measurements (Mandin et al., 2014, 2016) in airborne particulate matter and dust for most compounds, which were combined with a static partitioning model and human exposure factors. This two-dimensional Monte Carlo simulation revealed that the exposure variance was mainly driven by the contamination variability rather than by the uncertainty in modeling parameters. 
RfD is an estimate of a daily oral exposure that is likely to be without an appreciable risk of deleterious effects during a lifetime (US EPA 2002). For this risk assessment, RfDs based on oral exposure were preferred because they were available for most SVOCs. We retrieved RfDs, or their equivalents (minimal risk levels or acceptable daily intakes), from the following online databases: the Integrated Risk Information System (IRIS) from US EPA (https://www.epa.gov/iris), the toxicological profiles from Agency for Toxic Substances and Disease Registry (ATSDR) (https://www.atsdr.cdc.gov/), the Joint Meeting on Pesticide Residues (JMPR) from the WHO (http://apps.who.int/pesticide-residues-jmprdatabase/Home/Range/A-C), the Joint FAO/WHO Expert Committee on Food Additives (JECFA) (http://apps.who.int/food-additives-contaminants-jecfa-database/search.aspx), the Office of Environmental Health Hazard Assessment (OEHHA) (http://oehha.ca.gov/chemicals), Health Canada (https://www.canada.ca/en/healthcanada.html), the French agency for food, environment and occupational safety (ANSES) (https://www.anses.fr/fr), and the EU pesticide database from European Commission (http://www.efsa.europa.eu/). RfDs were selected according to the following criteria: i) status = final (non-provisional), ii) methods $=$ derived from classical dose-response data, and iii) update $=$ not the oldest value. Finally, where previous criteria were met for several RfDs, the most conservative was chosen (see Table S1). Where no RfDs were available for individual PCBs or PBDEs compounds, we made the assumption of similar toxic potency between congeners having the same molecular formula (same number of halogenated atoms) and used the RfD of the known congener. Because ADDs are internal doses, RfDs were converted into internal doses using oral bioavailability coefficients $\left(f_{\text {oral }}\right)$. These are the fraction of a contaminant reaching the digestive system and absorbed into the systemic circulation (Rostami and Juhasz 2011). See Table S2 for corresponding $\mathrm{f}_{\text {oral }}$ coefficient for each compound. Where RfDs were based on studies using adult mammals, the risk was assessed 
152 With

153

for the exposure of both an adult (aged 21 to 30 years, as an example) and a child (from birth to the age of 2 years, as an example) because the uncertainty factors applied for intra-species variability are supposed to take into account differences in the sensitivity of responses within a species (US EPA, 2008). Given that early-life (pre- and postnatal periods) is considered as a very vulnerable period, where RfDs were based on prenatal studies, the risk was assessed only for the exposure of a pregnant woman (aged 21-30 years, as an example). And where RfDs were based on postnatal studies, the risk was assessed only for the exposure of a child (from birth to the age of 2 years, as an example). Lastly, HQs were calculated for median and high uptake estimates (ADD $50^{\text {th }}$ and $95^{\text {th }}$ percentiles, respectively).

For genotoxic carcinogen SVOCs, excess risks (ER, unitless) were calculated as follows for an adult continuously exposed from birth to the age of 30 years:

$$
E R=\mathrm{ADD} \times\left(\mathrm{CSF} \times f_{\text {oral }}\right) \times \frac{E D}{L D}
$$

\section{CSF: Cancer slope factor $(\mathrm{mg} / \mathrm{kg}-\mathrm{bw} / \mathrm{d})^{-1}$}

ED: Exposure duration (30 years)

LD: Life duration (70 years)

$\mathrm{CSF}$ is an estimate of the increased cancer risk from oral exposure to a dose of $1 \mathrm{mg} / \mathrm{kg} / \mathrm{d}$ over a lifetime (US EPA 2005). CSFs were retrieved from literature using the same method as for RfDs (see Table S1). Finally, ERs were calculated for median and high uptake estimates (ADD 50 $0^{\text {th }}$ and $95^{\text {th }}$ percentiles, respectively).

\section{Cumulative risk assessment}


CRA methods are based on the assumption that additivity is plausible at low doses such as environmental exposures. In this assessment we did not consider potential interaction other than additivity. Among current literature referring to CRAs applied to SVOCs, most focus on methods using a hazard index (HI) or relative potency factors (RPF) (Pelletier et al., 2017b). The HI entails the addition of each chemical's risk indicator for SVOCs affecting common endpoints; it is considered a Tier 1 approach for CRA. RPFs rely on both the existence of a common biological endpoint (e.g. neuronal cell death) and high quality dose-response data for individual chemical on that endpoint, and so may be considered a higher tier method than HI. Similarly, the toxic equivalency factor (TEF) approach, specifically developed for dioxins and related compounds, relies on the existence of a clearly identified principal mechanism of action common to all chemicals included in the mixture and on having relative potency of each chemical relative to an index chemical for that mechanism (e.g. AhR activation). The RPF approach is considered a more general method and is used for other compounds such as PAHs, endocrine disruptors, and pesticides. Both the RPF and TEF approaches convert the dose of each compound into an index chemical-equivalent dose by scaling its toxicity relative to the index chemical.

Hereafter we present:

- Tier 1: estimation of HIs or ER for selected endpoints: neurotoxicity, reproductive toxicity, and genotoxicity.

- Tier 2: estimation of cumulative hazard quotients (CumHQ) or cumulative excess risks (CumER) using RPFs and TEFs published in the literature (it includes PAHs and gastro-intestinal cancer, PCB-DLs and activation of AhR, phthalates and antiandrogenic properties, different SVOCs and decreased testosterone levels or neuronal death) ; 
- Specific case for SVOCs with mixture based toxicological data (it includes only PCBs and immunotoxicity).

187

189

190

191

192

193

194

195

196

197

198

199

200

201

202

203

204

205

\section{$\underline{\text { Tier 1: }}$}

HI (unitless) is the sum of $n$ HQs for $n$ SVOCs, using equation (3):

$$
H I=\sum_{x=1}^{n} \frac{A D D_{x}}{R f D_{x} \times f_{\text {oral }_{x}}}
$$

In this risk assessment, we retrieved oral RfDs for neurotoxic and reprotoxic effects from the same databases as for the chemical-by-chemical assessment (see Tables S5 and S7). Where no RfD based on reprotoxic or neurotoxic endpoint was available, a literature survey was conducted in order to retrieve neurotoxic or reprotoxic points of departure (POD). Using the Web Of Knowledge ${ }^{\mathrm{TM}}$ website (Thomson Reuters,www.webofknowledge.com) publications were selected primarily by searching in the 'topic' field (title, abstract, and key words): ("SVOC name" AND (neurotoxicity OR (reproductive OR reprotoxic OR endocrine disruptor)). Secondly, abstract reading was used as a means of filtering out irrelevant publications. Next, study selection criteria included: i) in vivo oral exposure of mammals (by diet or gavage) and where possible ii) testing several (or at least one) dose(s) in comparison with a control group. Lastly, if previous criteria were met, PODs were chosen preferentially if benchmark doses (BMD) > no observed adverse effect level (NOAEL) > low observed adverse effect level (LOAEL). We found neurotoxic PODs for 17 SVOCs out of 32 and reprotoxic PODs for 15 SVOCs out of 32. RfDs were calculated by dividing the available POD by uncertainty factors (UF). UF were applied for intraspecies variability $\left(\mathrm{UF}_{\mathrm{H}}\right)$, interspecies variability $\left(\mathrm{UF}_{\mathrm{A}}\right)$, extrapolation from a LOAEL to a NOAEL $\left(\mathrm{UF}_{\mathrm{L}}\right)$, database deficiency $\left(\mathrm{UF}_{\mathrm{D}}\right)$, and extrapolation from acute/subchronic ( $<28$ days/28 to 90 days) to 
chronic exposure (> 90 days) $\left(\mathrm{UF}_{\mathrm{S}}\right)$ (US EPA 2008). $\mathrm{f}_{\text {oral }}$ coefficients were used to convert RfDs into internal doses (see Table S2). Finally, HIs were calculated for median and high uptake estimates (ADD 50 th and $95^{\text {th }}$ percentiles, respectively).

Benzo[a]pyrene and lindane are genotoxic compounds (cf. chemical-by-chemical risk assessment) but were not combined because they induce different types of tumors (i.e., gastrointestinal and liver respectively).

\section{Tier 2:}

We search the literature for available RPFs and TEFs or relative potencies for the 32 SVOCs included in this study. We found adequate data for: 2 PCBs for toxic effects mediated by the aryl hydrocarbon receptor (AhR) (Van den Berg 1998, 2006), 4 PAHs for carcinogenic effects (Ineris 2003), 3 and 5 phthalates (Benson et al., 2009; Hannas et al., 2011) for reprotoxic effects driven by anti-androgenic properties, and 4 SVOCs belonging to different chemical classes - PAHs and phthalates - for reprotoxic effects driven by a decrease in testosterone levels (Fournier et al., 2016). We also estimated RPFs from neuronal death relative potencies (i.e. comparable BMDs) published by Fournier et al. (2017) for 9 SVOCs: benzo[a]pyrene, diethylhexyl phthalate (DEHP), PCB 52, PCB 153, dieldrin, chlorpyrifos, lindane, BDE 47, and BDE 99 (see Table S9). In this last case, chlorpyrifos was chosen as the index compound based on the following criteria: i) well-known neurotoxic effect and ii) available RfDs from databases of good quality and covering as many age groups as possible.

RPFs (unitless) express the potency of a compound " $x$ " according to the index compound " $i$ " and were estimated as follows:

$$
R P F_{x}=\frac{B M D_{i}}{B M D_{x}}
$$


228 For non-carcinogenic SVOCs, CumHQs (unitless) were then calculated as follows for $\mathrm{n}$ 229 compounds:

$$
\text { CumHQ }=\frac{\sum_{x=1}^{n}\left(A D D_{x} \times R P F_{x}\right)}{R f D_{i} \times f_{\text {oral }_{i}}}
$$

Where $\mathrm{RfD}_{\mathrm{i}}$ is the RfD of the index compound. The same equation is used for the TEF approach, replacing the RPFs with TEFs.

For genotoxic carcinogen SVOCs, CumERs (unitless) were then calculated as follows for $\mathrm{n}$ compounds:

$$
\text { CumER }=\sum_{x=1}^{n}\left(A D D_{x} \times R P F_{x}\right) \times\left(C S F_{i} \times f_{\text {oral }_{i}}\right) \times \frac{E D}{L D}
$$

Where $\mathrm{CSF}_{\mathrm{i}}$ is the CSF of the index compound.

\section{Special case of PCBs:}

In addition for PCBs, we considered the mixture, because RfDs were directly available for industrial mixtures of PCBs (Aroclor). The RfD of $20 \mathrm{ng} / \mathrm{kg}$-bw/d for immunotoxic effect of Aroclor 1254 was chosen, because this mixture contains our 8 PCBs. This RfD was proposed by the US EPA in 1996 (US EPA 1996), and extended to the 209 PCBs congeners by the ATSDR (ATSDR 2000), RIVM (Baars et al. 2001) and Afssa (Afssa 2003). Because the 8 congeners included in this study (PCB 28, 31, 52, 101, 105, 118, 138, and 153) represent 34\% of the total composition of Aroclor 1254 (ATSDR 2000), we consider an RfD of $7 \mathrm{ng} / \mathrm{kg}$ bw/d (20*34/100) (see Table S10).

In this case $\mathrm{HI}$ (unitless) is estimated using equation (7):

$$
H I=\frac{\sum\left(A D D_{x} \times \frac{1}{f_{\text {oral }}}\right)}{R f D_{\text {Aroclor } 1254} \times 0,34}
$$




\section{RESULTS}

247

248

249

250

251

252

253

254

255

256

257

258

259

260

261

262

263

264

265

\section{Chemical-by-chemical risk assessment}

Risk assessment could be carried out for 21 SVOCs of the 32 initially considered: 19, 16, and

9 for the exposures of children, adults, and pregnant women respectively. Indeed, no RfDs were available in the databases for PCBs $(28,31,52,101,105,118,138$, and 153) and BDEs $(28,153$, and 154) or for their congeners having the same molecular formula.

ADD compared to oral $\mathrm{RfD} * \mathrm{f}_{\text {oral }}$ are presented in Figure 1 for the population having the highest HQ for each compound. HQs are $>1$ for part of the population if ADD box plot intersects the RfD. For di-isononyl phthalate (DiNP) and di-isobutyl phthalate (DiBP), RfDs were available only following in utero exposure (see Table S1), which enable risk assessments only for pregnant women exposure. Detailed HQs are presented in Table S3.

\section{[Figure 1]}

Health effects may occur for 3 SVOCs considered separately. HQs were above 1 for $50 \%$ of children for BDE 47 for reprotoxic effect, and for $5 \%$ of children for lindane for immunotoxic effect and dibutyl phthalate (DBP) for reprotoxic effect. For the other compounds, the risk associated with residential SVOC exposure may be considered as acceptable, according to common criteria, with HQs much lower than 1.

ERs of the genotoxic carcinogens: benzo[a]pyrene and lindane are shown in Figure 2. They are lower than $10^{-5}$ (Y axis) and may therefore be considered as acceptable (WHO 2008).

[Figure 2]

\section{Cumulative risk assessment}


17 SVOCs are included because there is evidence of neurotoxicity: 15, 6, and 6 were considered for the exposures of children, adults, and pregnant women, respectively, according to the windows of exposure considered in the toxicological testing available for the derivation of the RfD. Seven RfDs were retrieved from literature and 10 were constructed (see Table S5).

HIs were always below 1 (Figure 3 and Table S6 for detailed results). Neurotoxic risks for each age group may therefore be considered acceptable.

[Figure 3]

[Figure 4]

Figure 4 shows the relative contribution of each chemical to neurotoxic HIs for the exposures of children, adults and pregnant women. For the children's exposure, DEHP and DBP each contributed $22 \%$ and $42 \%$ to the $95^{\text {th }}$ percentile of HI respectively, followed by dieldrin (12\%). Other SVOCs contributed less than $10 \%$ each. For the adults' exposure, DBP contributed $59 \%$ to the $95^{\text {th }}$ percentile of $\mathrm{HI}$, followed by dieldrin (17\%), DiBP $(13 \%)$ and DEHP (12\%). Other SVOCs contributed less than 10\% each. For the pregnant women's exposure, lindane contributed to $47 \%$ of the neurotoxic risk for offspring, followed by PCB $52(39 \%)$ for the highest exposure. Other SVOCs contributed less than 5\% each. Similar results were found for the median exposure for all populations.

\section{Tier 1 assessment for the reprotoxic SVOCs:}

15 SVOCs are included because there is evidence of reproductive toxicity: 11,7 , and 9 were considered for the exposures of children, adults, and pregnant women, respectively, according 
to the windows of exposure considered in the toxicological testing available for the derivation of the RfD. Eleven RfDs were retrieved from literature and 5 were constructed (see Table S7).

Reprotoxic effects may occur for some mixtures. HIs were above 1 for $95 \%$ of children $\left(5^{\text {th }}\right.$ percentiles, data not shown), and close to 9 for $5 \%$ of them, for the mixture of 11 reprotoxic SVOCs. For the pregnant women's exposure, HIs were above 1 for $5 \%$ of them, for the mixture of 9 reprotoxic SVOCs (Figure 5). For adults, HIs were lower than 1 for the mixture of 7 SVOCs (see Table S8 for detailed results).

\section{[Figure 5]}

\section{[Figure 6]}

Figure 6 shows the relative contribution of each chemical to reprotoxic HIs for the exposures of children, adults and pregnant women. For the children's exposure, PCBs 101/118 contributed $45 \%$ to the $95^{\text {th }}$ percentile of HI, followed by BDE $47(25 \%)$ and DBP $(20 \%)$. Other SVOCs contributed less than $10 \%$ each. For the adults' exposure, dieldrin contributed $45 \%$ to the $95^{\text {th }}$ percentile of HI, followed by DEHP (31\%), benzo[a]pyrene (12\%) and DBP (10\%). Other SVOCs contributed less than $10 \%$ each. For the pregnant women's exposure, the sum of PCBs 101/118 contributed to 52\% of the reprotoxic risk for offspring, followed by DBP (47\%) for the highest exposure. Other SVOCs contributed less than 1\% each. Similar results were found for the median exposure for all populations (Figure 6).

\section{$\underline{\text { Tier } 2 \text { assessment: }}$}

[Table 1]

19 SVOCs are included in tier 2 according to the availability of RPF, relative potencies, or TEF in the literature. However, considering that TEF or RPF were derived from different biological endpoints, relatively simple mixtures, containing 2 to 9 compounds, were 
considered for each endpoint, as reported in Table 1. For children, neurotoxic effects via neuronal death due to a mixture of 9 SVOCs from different chemical classes were likely to occur for $95 \%$ of them $\left(\mathrm{HI}=1\right.$ at $5^{\text {th }}$ percentiles of exposure, data not shown). Toxic effects mediated by the AhR due to a mixture of 2 PCBs were likely to occur for $5 \%$ of children. Reprotoxic effects via a decrease in testosterone level due to a mixture of benzo[a]pyrene and 3 phthalates were likely to occur for $25 \%$ of children and $5 \%$ of adults. For pregnant women's exposure, CumHQs were below 1 for exposure to mixtures of 5 and 3 phthalates with antiandrogenic effects.

[Figure 7]

[Figure 8]

[Figure 9]

Figures 7, 8 and 9 show the relative contribution of each chemical to CumERs and CumHQs for each age group. PCB 105, diethyl phthalate (DEP), and DEHP contributed largely to the $50^{\text {th }}$ and the $95^{\text {th }}$ percentiles of CumHQs for both children's and adults' exposure (Figures 7 and 8). For the gastrointestinal cancer risk associated with $\mathrm{PAH}$ exposure of adults, benzo[a]pyrene contributed largely to the $50^{\text {th }}$ and the $95^{\text {th }}$ percentiles of CumER (Figure 8 ). For pregnant women's exposure, DBP and DiBP contributed most to the $50^{\text {th }}$ and the $95^{\text {th }}$ percentiles of CumHQs (Figure 9).

\section{$\underline{\text { Special case of PCBs: }}$}

Immunotoxic risks may occur for $5 \%$ of children because of exposure to the 8 PCBs. For adults and pregnant women's exposure, HIs were lower than 1 (Figure 10). 
A summary of the main findings for both chemical-by-chemical and cumulative risk assessments is presented in Figure 11.

[Figure 11]

\section{DISCUSSION}

Health risks posed by residential indoor exposure to 32 SVOCs in France were assessed. The chemical-by-chemical assessment revealed unacceptable risk for children because of their exposures to BDE 47 (reprotoxic effect), DBP (reprotoxic effect), and lindane (immunotoxic effect) (Figure 1). No unacceptable risks were identified for other chemicals and for adults or pregnant women.

The CRA approach identified additional risks: Tier 1 CRA revealed unacceptable reprotoxic risks (HI>1) for children and for pregnant women's exposure. The following SVOCs contributed most to the risk: PCB 101 and 118, BDE 47, and DBP (Figure 6). Tier 2 CRA showed that neurotoxic effects via neuronal death, due to a mixture of chlorpyrifos, benzo[a]pyrene, DEHP, PCB 52, PCB 153, dieldrin, lindane, BDE 47, and BDE 99 (Table 1), could be hazardous for children. Tier 2 also showed that reprotoxic effects were associated with a decrease in testosterone levels and might be hazardous for highly exposed children and adults, due to a mixture of benzo[a]pyrene, DEHP, DEP, and benzyl butyl phthalate (BBP) (Table 1). For toxic effects mediated by the AhR, exposure to PCB 105 and PCB 118 might be hazardous for highly exposed children (Table 1). Equal TEFs were estimated by the WHO (Van den Berg et al., 1998, 2006) for both compounds and we found PCB 105 to be the most contributive pollutant (Figures 7 and 8 ) only because its exposure was higher than PCB 118 (3 ng/kg-bw/d, p95 values for a children's exposure estimated from Pelletier et al. (2017b), data not shown). Lastly, the special case of PCBs CRA revealed unacceptable immunotoxic risk for children's exposure to 8 indoor PCBs (Figure 10). 
Study strengths include: i) CRA of numerous SVOCs from different chemical families for different populations, ii) use of nationwide representative exposure estimates, and iii) use of refined, tiered CRA approaches with HI, RPF and TEF being used successively.

Study limitations include the existence of uncertainties, mainly due to: i) the relevance of toxicological and epidemiological data for risk assessment, ii) the number of compounds included in the mixtures, iii) exposure data, and iv) RfD and RPF/TEF construction.

\section{Relevance of toxicological and epidemiological data for risk assessment}

The assessment requires a certain level of caution for accurate interpretation, due mainly to the transposition of effects from animal to human and the weight of evidence of the effect in humans.

For the first tier of the CRA approach, in terms of reprotoxic effects, no RfD for reprotoxic endpoint were available in literature for PCBs. The $\mathrm{RfD}_{\text {rep }}$ value we constructed for PCB 101 and 118 was based on decreased relative testes and ovary weight in offspring (F1 and F2) after subchronic exposure of pregnant mice from GD 0 to PND 21 (see Table S7). Human studies supported the endocrine-disrupting capacity of PCBs (Dallinga et al., 2002; Den Hond et al., 2002). Dallinga et al. (2002) observed a significantly decreased sperm count in relation to an elevated PCBs (included PCB 118) metabolites level in the blood of men with normal semen quality and Den Hond et al. (2002) showed a significant delay in puberty in boys (reduction in the genitals and lower testicular volume). These results confirmed the relevance of this endpoint for humans. For BDE 47 the RfD was based on a specific female endpoint: decreased uterus weight in 2 month-old female rats after a single exposure on postnatal day (PND) 10 (see Table S1). This endpoint appears relevant to humans. For phthalates, in particular DBP and DEHP, toxicity indicators were based on their anti-androgenic properties, which have been extensively studied (Gray et al., 2006; Kay et al., 2014). Furthermore, 
epidemiological and experimental studies have also confirmed their effects as endocrine disruptors as well as their reprotoxic effects on human health (Swan et al., 2005; Habert et al., 2009). This endpoint therefore appears relevant to humans.

In terms of immunotoxic effects, the RfD for lindane was based on biphasic changes in celland humoral-mediated immunity to red blood cells in adult female mice after chronic exposure (24 weeks) (see Table S1). Although the immunotoxic effects of lindane have been confirmed by other oral studies (Dorsey 2005), it is difficult to relate human health effects to specific immunotoxic parameters in laboratory animals due to the complexities of the immune system (Abadin et al., 2007) and this endpoint has not been studied in humans.

In the tier-2 CRA approach, the results concerning neurotoxic risk are surprising since the most contributive pollutant was DEHP (Figures 7 and 8). A first explanation is that exposure to this compound was much higher than for the others ( 2 to 4 orders of magnitude higher than PCBs, PBDEs, or organo-chlorinated pesticides, i.e., $2 \mu \mathrm{g} / \mathrm{kg}$-bw/d, p95 values for children's exposure estimated from Pelletier et al. (2017b), data not shown). In addition, the toxicity data used to derive its RPF indicate that DEHP is as potent as some insecticides (i.e., dieldrin or chlorpyrifos) in inducing neuronal cell death. These data were retrieved from the study of Lin et al. (2011), which found a 10\% decrease in neuronal viability in neuroblastoma cells of mice, starting at $10 \mu \mathrm{M}$. DEHP is best known for its reproductive toxicity as an antiandrogenic compound. However, recent animal studies have shown that it may induce toxic effects in the rat brain (Guida et al., 2014). Associations between human phthalate exposure, including DEHP, and impairment of cognitive development, school-age intelligence, and autism spectrum disorders have also been suggested (Cho et al. 2010, Kobrosly et al. 2014, Yolton et al. 2011). While these observations are based only on limited studies, they are of concern and lead us to recommend further studies to better understand the neurotoxicity of phthalates, as suggested by Miodovnick et al. (2014). 
The results concerning the tier- 2 reprotoxic risk associated with a decrease in testosterone level may also be considered surprising in the particular case of DEP, which is highlighted as the most contributive pollutant (Figures 7 and 8). Our use of data from the study of Pereira et al. (2008) could explain this result. The authors found a 10\% decrease in testosterone levels in rats starting from $0.24 \mathrm{mg} / \mathrm{kg}$-bw/d. DEP is usually not considered to be as toxic as other long-chain phthalate esters (i.e., DEHP or DBP), based on toxicity studies that have produced inconsistent results. Some studies showed negative results in rodents exposed at high doses (Api 2001) but others showed lower reproductive performance in mice and decreased serum testosterone levels in rats (NTP 1984, Fujii et al. 2005). A mechanistic hypothesis explaining this potential reproductive effect may not be related to Sertoli cell impairment, as for other phthalates. Rather, it might be explained by indirect action on Leydig cells, with lipid peroxidation and decreased antioxidant defense at the testicular level (Pereira et al., 2008). Epidemiological studies in humans have also suggested associations between DEP exposure (metabolite measurement) and sperm modifications (Duty et al., 2003; Duty et al., 2004; Hauser et al., 2006), but again, results have been inconsistent (Lottrup et al., 2006; Matsumoto et al., 2008). DEP exposure in these studies may be a surrogate for other risk factors associated with reproductive disorders, as suggested by some authors (Hauser et al., 2006). Moreover DEP did not appear among the SVOCs contributing to health risks to pregnant women (Table 1, Figure 9) because no relative potencies have been published for this specific window of exposure. DEP does not appear to induce a reduction in fetal testosterone and insulin-like growth factor-3, as other phthalates do (Gray et al., 2000).

Similarly,

For PCBs (sum of 8 congeners), the RfD of the Tier 2 assessment was based on immunological effects in adult monkeys (see Table S10). Monkeys appeared more sensitive than other species (rats, mice, guinea pigs and rabbits) for effects on antibody responses after 
oral exposure and provided a better animal model due to phylogenetic and biological similarities to humans (Tryphonas 1994, 1995). However, the exposure-response relationship between PCB exposure and altered immune functions in humans has not yet been fully documented, and only suggestive evidence is shown (Levin et al, 2005).

To summarize, given the present state of knowledge, critical reprotoxic effects appear relevant to humans for indoor exposure to PCB 101 and PCB 118, DEP, DBP, and to a lesser extent, BDE 47. Similar conclusions could be drawn about the immunotoxicity of PCBs, based primarily on consistent results from animal data. The specific case of DEP should, however, be interpreted with caution due to inconsistent results for the toxicological data. It is possible that DEP may act through an alternative mechanism involving oxidative stress (Pereira et al., 2008). This should be investigated in further studies. For phthalates (DEHP and DBP), extrapolation of neurotoxicity data from animal models to humans has led to a lower level of confidence, but some recent epidemiological data suggest neurobehavioral impairment and lead us to recommend further studies. The same conclusion could be reached for lindane, although its immunotoxicity in humans has not been studied.

\section{Selected compounds and missing data}

The refinement of this risk assessment by using a tier-2 approach strongly depends on the availability of data on the mode or mechanism of action, which influences the number of compounds included in the mixtures. For example, the RPF and TEF approaches were conducted for mixtures of only 2 PCBs for toxic effects mediated by the AhR, without including other compounds known to be capable of binding to the AhR (such as organochlorine, brominated compounds or PAHs), because no RPFs or TEFs are available in the literature. It is also the reason why only 4 SVOCs and 5 or 3 phthalates were included for reprotoxic effects and only 9 SVOCs for neurotoxic effects (Table 1). We also made a 
distinction between pre- and postnatal periods and adulthood, and this resulted in studying different mixtures containing different SVOCs for each age group, e.g. neurotoxic CRA was conducted for 15 compounds for the children's exposure, for 9 compounds for the adults' exposure, and for 6 compounds for the pregnant women's exposure (Figure 3). In terms of effects, age-related differences in susceptibility to contaminants are due to the fact that critical periods of structural and functional development are happening during pre- and postnatal life. The nervous, immune, respiratory, reproductive and endocrine systems are in a particularly sensitive stage of development at these early periods of life (Selevan et al., 2000). Increasing evidence of sensitive populations, in terms of exposure and toxic effects, demands clearer distinctions between the different windows of exposure (US EPA 2002), in particular to avoid either overestimation of the risk for adults in cases where data are available only for juveniles or gestating mammals or underestimation of the risk for pregnant women when data are available only for adults. Thorough studies may allow the inclusion of new compounds in the different mixtures, which could raise the risk - for example, HI for children's exposure to 15 neurotoxic SVOCs was found to be 0.6 , but could reach (or even exceed) 1 were other SVOCs to be included.

Regarding exposure, the main limitation is that, despite the relatively high number of SVOCs considered compared to other works, many could not be included in this study because they were not assessed by our previous exposure research (Pelletier et al., 2017b), e.g., pyrethroids, bisphenols, etc. The most obvious example is the absence of most PAHs (only 3 of them were considered) and other carcinogenic compounds in the carcinogenic risk estimation. Our conclusions are therefore limited to the SVOCs studied, and health risks are necessarily underestimated, as the question actually addressed is narrower than that of the risk posed by SVOCs in general. This limitation also affects the contribution of particular compounds to the risk for a given endpoint. 


\section{Exposure data}

482 Uncertainty in results may also be due to the exposure data. However, ADDs were estimated 483 using a probabilistic approach and two-dimensional Monte Carlo simulations. Compared to a 484 more traditional deterministic approach, this has the main advantage of taking into account 485 both uncertainty (lack of knowledge about a parameter) and variability (heterogeneity of a 486 parameter in a population) of input parameters. The sensitivity analysis conducted by Pelletier 487 et al. (2017b) revealed that exposure estimate variance was mainly driven by indoor 488 contamination variability $\left(\mathrm{C}_{\text {gas }}, \mathrm{C}_{\text {part }}\right.$ and $\left.\mathrm{C}_{\text {dust }}\right)$, and only secondarily by uncertainty in 489 physical and chemical parameters. Furthermore, because ADDs decrease with age (due to the 490 increased body weight), where risks related to a single effect could be estimated for several 491 age groups, they were always higher for those children exposed from birth to the age of 2 492 years. These exposure estimates were found to be consistent with those from studies similar in 493 terms of levels of exposures and predominant pathways. Because risks were assessed for the $49495^{\text {th }}$ percentile of exposure, risks may be underestimated for the most exposed, given that 495 exposure concentrations above the $95^{\text {th }}$ percentile are skewed and often can be much higher at 496 the $99^{\text {th }}$ percentile.

Toxicity indicators

498 The uncertainty linked to RfD construction may also strongly influence the results. For 499 several compounds that are at risk, the RfDs had a UF as high as 1,000 (i.e. BDE 47, DBP, 500 and lindane) or even 3,000 (i.e. PCB 101 and PCB 118) - this could be considered as low 501 confidence, reflecting major uncertainties in the databases and in particular because of using 502 LOAELs instead of NOAELs and BMDs. Furthermore, internal RfDs were estimated using 503 oral bioavailability coefficients. Averaged values for $f_{\text {oral }}$ were used (see Table S2). For 504 chemical-by-chemical risk assessment, internal RfDs were also estimated using the minimum 
and maximum values (data not shown) of $\mathrm{f}_{\text {oral }}$ distributions from Pelletier et al. (2017b). HQ results could be up to 10 times higher when using minimum $f_{\text {oral }}$ values and up to 2 times lower when using maximum $\mathrm{f}_{\text {oral }}$ values for some SVOCs having broad distribution for this parameter (e.g. lindane and dieldrin). The most contrasted example is lindane, with an HQ of 22 when using the minimum value and of 1 when using the maximum value (for the p95 of children's exposure). However, although results may vary depending on the $f_{\text {oral }}$ value, identification of the compounds that are at risk remains unchanged. Uncertainties could also be related to the read-across extrapolations, required where some of the congeners lacked toxicological data, i.e. RfDs for BDE and PCB congeners. Finally, for RPF and TEF construction, the uncertainties mainly depend on data comparability: for example concerning different exposure routes (intratracheal, breast implants, and cutaneous contact) (Ineris 2003), endpoints (decrease in fetal testosterone level for all phthalates versus smallness - or absence of - male reproductive organs for DEHP) (Benson 2009), windows of exposure (prenatal, postnatal, and adult), and types of experimental systems (cell lines versus primary cultures), strains (mice, rats, and humans) and types of cells (e.g. pheochromocytoma versus neuroblastoma cells) (Fournier et al., 2017).

\section{CONCLUSIONS}

This risk assessment, notably its cumulative aspect, allowed the identification of residential aggregated indoor exposures that lead to unacceptable risk for a certain portion of the French population. Furthermore, it allowed the identification of the most contributive compounds for different health effects namely DBP, DEP, DEHP, BDE 47, lindane, and PCBs. Based on evidence for effects in humans, it is thus possible to prioritize chemicals for prevention (DBP, DEP, and some PCBs), while simultaneously taking indoor contribution to total exposure and the effectiveness of prevention measures into account. This work also makes it possible to prioritize supplemental scientific studies to clarify their impact in terms of risk to human 
530 health, especially neurologic effects of phthalates and, to a lesser extent, reproductive effects

531 of BDE 47, and immunotoxic effects of lindane and PCBs. More generally, to enable a

532 broader cumulative risk assessment, it seems important to ensure that contamination data

533 encompass new chemicals and that toxicological studies are comparable and publicly

534 available. Finally, it is interesting to note that in certain cases, i.e. exposure to neurotoxic

535 compounds, Tier 1 assessments were less conservative than Tier 2 assessments. This finding

536 reveals that for cumulative risks, a lower-tier assessment may not be sufficient in every case. 


\section{REFERENCES}

538

539

540

541

542

543

544

545

546

547

548

549

550

551

552

553

554

555

556

557

Abadin, H. G., Chou, C. H., \& Llados, F. T. (2007). Health effects classification and its role in the derivation of minimal risk levels: immunological effects. Regul. Toxicol. Pharm., 47(3), 249-256.

Afssa - Agence française de sécurité sanitaire des aliments (2003). Avis du 8 avril 2003 sur l'existence éventuelle d'une corrélation significative entre les teneurs des différents congénères de PCB. https://www.anses.fr/fr/system/files/RCCP2002sa0149.pdf.

Api, A. M. (2001). Toxicological profile of diethyl phthalate: a vehicle for fragrance and cosmetic ingredients. Food and Chemical Toxicology, 39(2), 97-108.

ATSDR - Agency for Toxic Substances and Disease Registry (1995). Toxicological profile for Polycyclic Aromatic Hydrocarbons (PAHs). Atlanta, GA: U.S. Department of Health and Human Services, Public Health Service.

ATSDR - Agency for Toxic Substances and Disease Registry (2000). Toxicological profile for Polychlorinated Biphenyls (PCBs). Atlanta, GA: U.S. Department of Health and Human Services, Public Health Service.

ATSDR - Agency for Toxic Substances and Disease Registry (2002). Toxicological profile for Di(2-ethylhexyl)phthalate (DEHP). Atlanta, GA: U.S. Department of Health and Human Services, Public Health Service.

ATSDR - Agency for Toxic Substances and Disease Registry (2005). Toxicological profile for Hexachlorocyclohexane. Atlanta, GA: U.S. Department of Health and Human Services, Public Health Service. 
Baars, A. J., Theelen, R. M. C., Janssen, P. J. C. M., Hesse, J. M., van Apeldoorn, M. V., Meijerink, M. V., Verdam, M.J., Zeilmaker, M. J. (2001). Re-evaluation of humantoxicological maximum permissible risk levels. RIVM report 711701025.

Benson, R. (2009). Hazard to the developing male reproductive system from cumulative exposure to phthalate esters - dibutyl phthalate, diisobutyl phthalate, butylbenzyl phthalate, diethylhexyl phthalate, dipentyl phthalate, and diisononyl phthalate. Regul. Toxicol. Pharm., 53(2), 90-101.

Blanchard, O., Glorennec, P., Mercier, F., Bonvallot, N., Chevrier, C., Ramalho, O., Mandin, C., \& Le Bot, B. (2014). Semivolatile organic compounds in indoor air and settled dust in 30 French dwellings. Environ. Sci. Technol. 48, 3959-3969

Boobis, A. R., Ossendorp, B. C., Banasiak, U., Hamey, P. Y., Sebestyen, I., \& Moretto, A. (2008). Cumulative risk assessment of pesticide residues in food. Toxicol. Lett., 180(2), 137-150.

Cho, S. C., Bhang, S. Y., Hong, Y. C., Shin, M. S., Kim, B. N., Kim, J. W., Yoo, H.J., Cho, I.H., Kim, H. W. (2010). Relationship between environmental phthalate exposure and the intelligence of school-age children. Environmental health perspectives, 118(7), 1027.

Dallinga, J. W., Moonen, E. J., Dumoulin, J., Evers, J. L., Geraedts, J. P., \& Kleinjans, J. (2002). Decreased human semen quality and organochlorine compounds in blood. Hum. Reprod., 17(8), 1973-1979.

Den Hond, E., Roels, H. A., Hoppenbrouwers, K., Nawrot, T., Thijs, L., Vandermeulen, C.,... \& Staessen, J. A. (2002). Sexual maturation in relation to polychlorinated aromatic 
hydrocarbons: Sharpe and Skakkebaek's hypothesis revisited. Environ. Health Persp., 110(8), 771.

582

583

Dorsey, A. (2005). Toxicological Profile for Alpha-, Beta-, Gamma, and Deltahexachlorocyclohexane. Agency for Toxic Substances and Disease Registry.

Duty, S. M., Silva, M. J., Barr, D. B., Brock, J. W., Ryan, L., Chen, Z., Herrick, R.; C Christiani, D., Hauser, R. (2003). Phthalate exposure and human semen parameters. Epidemiology, 14(3), 269-277.

Duty, S. M., Calafat, A. M., Silva, M. J., Brock, J. W., Ryan, L., Chen, Z., Overstreet, J., Hauser, R. (2004). The relationship between environmental exposure to phthalates and computer-aided sperm analysis motion parameters. Journal of andrology, 25(2), 293302.

EFSA (2008). Panel on Plant Protection Products and their Residues (PPR) Scientific Opinion on a request from the EFSA evaluate the suitability of existing methodologies and, if appropriate, the identification of new approaches to assess cumulative and synergic risks from pesticides to human health with a view to set MRLs for those pesticides in the frame of Regulation (EC) 396/2005. EFSA J., 704, 1-85. https://www.efsa.europa.eu/en/efsajournal/pub/705.

Fournier, K., Glorennec, P., \& Bonvallot, N. (2014a). Construction de valeurs toxicologiques de référence adaptées à la prise en compte des mélanges en évaluation des risques sanitaires: méthodes existantes et applications récentes. Envir. Risques Santé, 13(3), 203-221. 
Fournier, K., Glorennec, P., \& Bonvallot, N. (2014b). An exposure-based framework for grouping pollutants for a cumulative risk assessment approach: Case study of indoor semi-volatile organic compounds. Environ. Res., 130, 20-28.

Fournier, K., Tebby, C., Zeman, F., Glorennec, P., Zmirou-Navier, D., \& Bonvallot, N. (2016). Multiple exposures to indoor contaminants: Derivation of benchmark doses and relative potency factors based on male reprotoxic effects. Regul. Toxicol. Pharm., 74, 23-30.

Fournier, K., Baumont, E., Glorennec, P., \& Bonvallot, N. (2017). Relative toxicity for indoor semi volatile organic compounds based on neuronal death. Toxicol. Lett., 279, 33-42.

Fujii, S., Yabe, K., Furukawa, M., HIRATA, M., KIGUCHI, M., \& IKKA, T. (2005). A twogeneration reproductive toxicity study of diethyl phthalate (DEP) in rats. The Journal of toxicological sciences, 30(Special), S97-116.

Glorennec P., Mercier F., Blanchard O., Bonvallot N., Ramalho O., Mandin C. \& Le Bot B. (2011). Cumulative indoor exposures to Semi-Volatile Organic Compounds (SVOCs) in France: the ECOS project. Indoor Air Conference.Austin,TX,USA; 2011. http://hal.archives-ouvertes.fr/hal-00688091. Proceedings of meeting held 5-10 June 2011, Austin, $\quad$ Texas. ISBN: 9781627482721. http://www.proceedings.com/18032.html.

Gray Jr, L. E., Ostby, J., Furr, J., Price, M., Veeramachaneni, D. R., \& Parks, L. (2000). Perinatal exposure to the phthalates DEHP, BBP, and DINP, but not DEP, DMP, or DOTP, alters sexual differentiation of the male rat. Toxicological Sciences, 58(2), 350365. 
Gray, L. E., Wilson, V. S., Stoker, T., Lambright, C., Furr, J., Noriega, N.,... \& Guillette, L. (2006). Adverse effects of environmental antiandrogens and androgens on reproductive development in mammals. Int. J. Androl., 29(1), 96-104.

Guida, N., Laudati, G., Galgani, M., Santopaolo, M., Montuori, P., Triassi, M., Di Renzoa, G., Canzoniero, L., Formisano, L. (2014). Histone deacetylase 4 promotes ubiquitindependent proteasomal degradation of $\mathrm{Sp} 3$ in $\mathrm{SH}-\mathrm{SY} 5 \mathrm{Y}$ cells treated with di (2ethylhexyl) phthalate (DEHP), determining neuronal death. Toxicology and applied pharmacology, 280(1), 190-198.

Habert, R., Muczynski, V., Lehraiki, A., Lambrot, R., Lécureuil, C., Levacher, C.,... \& Rouiller-Fabre, V. (2009). Adverse effects of endocrine disruptors on the foetal testis development: focus on the phthalates. Folia Histochem. Cyto., 47(5), S67-S74.

Hannas, B. R., Lambright, C. S., Furr, J., Howdeshell, K. L., Wilson, V. S., \& Gray Jr, L. E. (2011). Dose-response assessment of fetal testosterone production and gene expression levels in rat testes following in utero exposure to diethylhexyl phthalate, diisobutyl phthalate, diisoheptyl phthalate, and diisononyl phthalate. Toxicol. Sci., 123(1), 206-216.

Hauser, R., Meeker, J. D., Singh, N. P., Silva, M. J., Ryan, L., Duty, S., \& Calafat, A. M. (2006). DNA damage in human sperm is related to urinary levels of phthalate monoester and oxidative metabolites. Human reproduction, 22(3), 688-695.

IARC Working Group on the Evaluation of Carcinogenic Risks to Humans. (2010). Some non-heterocyclic polycyclic aromatic hydrocarbons and some related exposures, IARC Monog. Eval. Carc., 92, 1. 
Ineris (2003). Hydrocarbures aromatiques polycycliques (HAPs). Évaluation de la relation dose-réponse pour des effets cancérigènes : Approche substance par substance (facteurs d'équivalence toxique - FET) et approche par mélanges. Évaluation de la relation dose-réponse. Institut National de l'Environnement et des Risques. Verneuil en Halatte, France. 2003. https://www.ineris.fr/fr/hydrocarbures-aromatiquespolycycliques-haps

Inserm (2013). Expertise collective : Pesticides - Effets sur la santé. ISBN 978-2-85598-906X. https://www.inserm.fr/thematiques/sante-publique/expertises-collectives.

Kay, V. R., Bloom, M. S., \& Foster, W. G. (2014). Reproductive and developmental effects of phthalate diesters in males. Crit. Rev. Toxicol., 44(6), 467-498.

Kobrosly, R. W., Evans, S., Miodovnik, A., Barrett, E. S., Thurston, S. W., Calafat, A. M., \& Swan, S. H. (2014). Prenatal phthalate exposures and neurobehavioral development scores in boys and girls at 6-10 years of age. Environmental health perspectives, 122(5), 521.

Levin, M., Morsey, B., Mori, C., Nambiar, P. R., \& De Guise, S. (2005). Non-coplanar PCBmediated modulation of human leukocyte phagocytosis: a new mechanism for immunotoxicity. Journal of Toxicology and Environmental Health, Part A, 68(22), 1977-1993.

Lin, C. H., Chen, T. J., Chen, S. S., Hsiao, P. C., \& Yang, R. C. (2011). Activation of Trim17 by PPAR $\gamma$ is involved in Di (2-ethylhexyl) phthalate (DEHP)-induced apoptosis on Neuro-2a cells. Toxicology letters, 206(3), 245-251. 
Lottrup, G., Andersson, A. M., Leffers, H., Mortensen, G. K., Toppari, J., Skakkebaek, N. E., \& Main, K. M. (2006). Possible impact of phthalates on infant reproductive health. International journal of andrology, 29(1), 172-180.

Mandin C., Mercier F., Lucas J-P., Ramalho O., Blanchard O., Bonvallot N., Raffy G., Gilles E., Glorennec P., \& Le Bot B (2014). ECOS-POUSS: A Nationwide Survey of SemiVolatile Organic Compounds in Home Settled Dust. Proceedings of the Indoor Air conference 2014, July 7-12 2014, Hong Kong, Vol. VI, 143-148.

Mandin, C., Mercier, F., Ramalho, O., Lucas, J. P., Gilles, E., Blanchard, O., Bonvallot, N., Glorennec, P., and Le Bot, B. (2016). Semi-volatile organic compounds in the particulate phase in dwellings: A nationwide survey in France. Atmos. Environ., 136, $82-94$.

Matsumoto, M., Hirata-Koizumi, M., \& Ema, M. (2008). Potential adverse effects of phthalic acid esters on human health: a review of recent studies on reproduction. Regulatory Toxicology and Pharmacology, 50(1), 37-49.

Meek, M. E., Boobis, A. R., Crofton, K. M., Heinemeyer, G., Van Raaij, M., \& Vickers, C. (2011). Risk assessment of combined exposure to multiple chemicals: a WHO/IPCS framework. Regul. Toxicol. Pharm., 60(2 suppl 1), S1-S14.

Mercier F., Glorennec P., Thomas O., Le Bot B. (2011). Organic contamination of settled house dust: a review for exposure assessment purposes. Environ. Sci. Technol., 45, 6716-6727.

Mercier F., Glorennec P., Blanchard O., Le Bot B (2012). Analysis of semi-volatile organic compounds in indoor suspended particulate matter by thermal desorption coupled with gas chromatography / mass spectrometry. Journal of Chromatography A; 1254:107-14. 
Mercier, F., Gilles, E., Saramito, G., Glorennec, P., Le Bot, B. (2014). A multi-residue method for the simultaneous analysis in indoor dust of several classes of semi-volatile organic compounds by pressurized liquid extraction and gas chromatography/tandem mass spectrometry. J. Chromatogr. A 1336, 101-111

Miodovnik, A., Edwards, A., Bellinger, D. C., \& Hauser, R. (2014). Developmental neurotoxicity of ortho-phthalate diesters: review of human and experimental evidence. Neurotoxicology, 41, 112-122.

NTP 1984. Diethyl phthalate: reproduction and fertility assessment in CD-1 mice when administered in the feed. Research Triangle Park, NC, US Department of Health and Human Services, National Institutes of Health, National Toxicology Program (NTP84-262) (1984).

Pelletier, M., Bonvallot, N., Ramalho, O., Mandin, C., Wei, W., Raffy, G., Mercier, F., Blanchard, O., Le Bot, B., \& Glorennec, P. (2017a). Indoor residential exposure to semivolatile organic compounds in France. Environ. Int., in press.

Pelletier, M., Bonvallot, N., \& Glorennec, P. (2017b). Aggregating exposures \& cumulating risk for semivolatile organic compounds: A review. Environ. Res., 158, 649-659.

Pereira, C., Mapuskar, K., \& Rao, C. V. (2008). Effect of diethyl phthalate on rat testicular antioxidant system: A dose-dependent toxicity study. Pesticide biochemistry and physiology, 90(1), 52-57.

Rostami, I., \& Juhasz, A. L. (2011). Assessment of persistent organic pollutant (POP) bioavailability and bioaccessibility for human health exposure assessment: a critical review. Crit. Rev. Env. Sci. Tec., 41(7), 623-656. 
Sarigiannis, D. A., \& Hansen, U. (2012). Considering the cumulative risk of mixtures of chemicals-a challenge for policy makers. Environ. Health, 11(1), S18.

Selevan, S. G., Kimmel, C. A., \& Mendola, P. (2000). Identifying critical windows of exposure for children's health. Environ. Health Persp., 108(Suppl 3), 451.

Swan, S. H., Main, K. M., Liu, F., Stewart, S. L., Kruse, R. L., Calafat, A. M.,... \& Teague, J. L. (2005). Decrease in anogenital distance among male infants with prenatal phthalate exposure. Environ. Health Persp., 1056-1061.

Tryphonas, H. (1994). Immunotoxicity of polychlorinated biphenyls: present status and future considerations. In Dioxins and the Immune System (pp. 149-162). Karger Publishers.

Tryphonas, H. (1995). Immunotoxicity of PCBs (aroclors) in relation to Great Lakes. Environ. Health Persp., 103(Suppl 9), 35.

US EPA (1996). PCBs: Cancer Dose-Response Assessment and Application to Environmental Mixtures. U.S. Environmental Protection Agency, Office of Research and Development, National Center for Environmental Assessment, Washington Office, Washington, DC, EPA/600/P-96/001F, 1996.

US EPA (2002). A Review of the Reference Dose and Reference Concentration Processes. U.S. Environmental Protection Agency, Risk Assessment Forum, Washington, DC, EPA/630/P-02/002F.

US EPA (2005). Guidelines for carcinogen risk assessment. U.S. Environmental Protection Agency, Risk Assessment Forum, Washington, DC, EPA/630/P-03/001F. 
US EPA Integrated Risk Information System (IRIS) Glossary. https://www.epa.gov/iris/basicinformation-about-integrated-risk-information-system\#guidance) Environmental Protection Agency (2008). IRIS Glossary. http://www.epa.gov/iris.

Van den Berg, M., Birnbaum, L., Bosveld, A. T., Brunström, B., Cook, P., Feeley, M.,... \& Kubiak, T. (1998). Toxic equivalency factors (TEFs) for PCBs, PCDDs, PCDFs for humans and wildlife. Environ. Health Persp., 106(12), 775.

Van den Berg, M., Birnbaum, L. S., Denison, M., De Vito, M., Farland, W., Feeley, M.,... \& Rose, M. (2006). The 2005 World Health Organization reevaluation of human and mammalian toxic equivalency factors for dioxins and dioxin-like compounds. Toxicol. Sci., 93(2), 223-241.

Weschler, C. J., \& Nazaroff, W. W. (2008). Semivolatile organic compounds in indoor environments. Atmos. Environ., 42(40), 9018-9040.

Weschler, C. J., \& Nazaroff, W. W. (2010). SVOC partitioning between the gas phase and settled dust indoors. Atmos. Environ., 44(30), 3609-3620.

World Health Organization. (2008). Guidelines for drinking-water quality [electronic resource]: incorporating 1st and 2nd addenda, vol. 1, Recommendations.

Yolton, K., Xu, Y., Strauss, D., Altaye, M., Calafat, A. M., \& Khoury, J. (2011). Prenatal exposure to bisphenol A and phthalates and infant neurobehavior. Neurotoxicology and teratology, 33(5), 558-566. 
Table 1: Cumulative hazard quotient (CumHQ) and cumulative excess risk (CumER) using toxic equivalency factors (TEF) and relative potency factors (RPF).

Figure 1: Comparison between residential indoor aggregate daily doses $\left(5^{\text {th }}, 25^{\text {th }}, 75^{\text {th }}\right.$, and $95^{\text {th }}$ percentiles) with internal reference doses $\left(\mathrm{RfD}^{*} \mathrm{f}_{\text {oral }}\right)$ represented by dots. Unit is $\mathrm{mg} / \mathrm{kg}$ bw/d. France 2003-2011.

Figure 2: Excess risk for residential indoor exposure to benzo[a]pyrene and lindane $\left(50^{\text {th }}\right.$ and $95^{\text {th }}$ percentiles) for an adult continuously exposed from birth to the age of 30 years. France 2003-2011.

Figure 3: Hazard index for neurotoxic effects due to residential exposure to indoor SVOCs (50 ${ }^{\text {th }}$ and $95^{\text {th }}$ percentiles). France $2003-2011$.

Figure 4: Relative contribution of chemicals to the neurotoxic hazard index.

Figure 5: Hazard index for reprotoxic effects due to residential exposure to indoor SVOCs $\left(50^{\text {th }}\right.$ and $95^{\text {th }}$ percentiles). France $2003-2011$.

Figure 6: Relative contribution of chemicals to the reprotoxic hazard index.

Figure 7: Relative contribution of chemicals to cumulative hazard quotients for children's exposure.

Figure 8: Relative contribution of chemicals to cumulative hazard quotients and cumulative excess risks for adults' exposure.

Figure 9: Relative contribution of chemicals to cumulative hazard quotients for pregnant women's exposure.

Figure 10: Hazard index for immunotoxic effects due to residential exposure to indoor PCBs $\left(50^{\text {th }}\right.$ and $95^{\text {th }}$ percentiles). France $2003-2011$. 
772 Figure 11: Summary of the main results of the chemical-by-chemical and cumulative risk

773 assessment. 